Artykuly / Articles

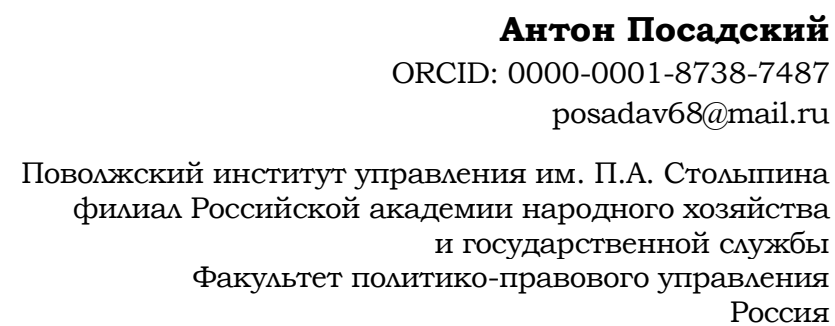

Россия

\title{
Историческая память как фактор жизнестойкости ${ }^{1}$
}

\author{
Historical Memory as a Factor of Resilience \\ Pamięć historyczna jako czynnik wytrwałości życiowej
}

DOI: $10.34739 /$ doc.2021.18.11

\begin{abstract}
Аннотация: Статья посвящена сохранению исторической памяти об эпохе Гражданской войны в России. Автор показывает рост интереса к тематике исторической памяти в последние десятилетия. Память о событиях Грахданской войны оказывается очень неравномерной. Память побежденных, но не ушедших в эмиграцию, оказывается практически невостребованной. Данная ситуация дает искаженную картину событий 1917-1922 гг. в современном массовом сознании. Автор обращает внимание на особенности мокальной памяти о событиях Гражданской войны и оценивает исследовательские возможности по востребованию памяти о событиях столетней давности.
\end{abstract}

Кмючевые слова: Россия, Гражданская война, историческая память, мокальная история

Abstract: The article is devoted to preserving the historical memory of the civil war in Russia. The author shows the growing interest in the subject of historical memory in recent decades. The memory of the events of the civil war is very uneven. The memory of those who were defeated, but did not go into exile, is almost unclaimed. This situation gives a distorted picture of the events of 1917-1922 in the modern mass consciousness. The author draws attention to the

\footnotetext{
1 Статья подготовмена при поддержке РФФИ, проект 18-00-00813 «Патриархальный мир и факторы жизнестойкости насемения в период „долгой войны” 1914-1922 годов".
} 
peculiarities of local memory of the events of the civil war and evaluates the research opportunities for the demand for memory of events of a century ago.

Keywords: Russia, civil war, historical memory, local history

Streszczenie: Artykuł poświęcony jest zachowaniu pamięci historycznej o okresie wojny domowej w Rosji. Autor ukazuje wzrost zainteresowania ta tematyka w ostatnich dziesięcioleciach. Pamięć o wydarzeniach wojny domowej jest jednak bardzo nierównomierna. Pamięć o zwyciężonych, którzy nie wyemigrowali, okazuje się niepożądana. Przyczynia się to do formowania zniekształconego obrazu wydarzeń z lat 1917-1922 we współczesnej świadomości. Autor zwraca uwage na specyfikę lokalnej pamięci o dziejach wojny domowej i ocenia możliwości badawcze, sprzyjajace pobudzeniu zainteresowania wydarzeniami sprzed stu lat.

Słowa kluczowe: Rosja, wojna domowa, pamięć historyczna, historia lokalna

В последние десятилетия на Западе активно обсуждается проблематика исторической и комлективной памяти, мемориализации истории. Используется даже выражение "мемориальная революция". Память в этом контексте следует рассматривать как один из ресурсов адаптивности и жизненной стойкости социума, как в самих фрустрирующих событиях, так и их последующем переживании.

Согласно М. Хальбваксу, "история обычно начинается в тот момент, когда заканчивается традиция, когда затухает или распадается социальная память. Пока воспоминание продолжает существовать, нет необходимости фиксировать его письменно, да и вообще как-либо фиксировать» ${ }^{2}$ В общем виде, у автора получается следующий вывод: «Когда память о некой череде событий перестает поддерживаться какой-либо группой, которая в них участвовала или испытала на себе их последствия, которая была их свидетелем или усмышала живой рассказ о них от первых участников или наблюдателей, когда эта память распыляется по нескольким индивидуальным сознаниям, затерянным в новых обществах, которые уже не интересуются этими событиями, потому что они дмя них опредеменно явцяются внешними, тогда спасти эти воспоминания можно, только письменно зафиксировав их в форме связного

\footnotetext{
2 М. Хальбвакс, Коллективная и историческая память, „Неприкосновенный запас", 2005, № 2, https://magazines.gorky.media/nz/2005/2/kollektivnaya-iistoricheskaya-pamyat.html (дата доступа: 28.11.2020).
} 
рассказа»3. Соответственно, возникает и тема забвения. Алейда Ассман, в предисловии к Формам забвения, указывает на то, что забвение значит гораздо больше, нежели просто слабость памяти. Поэтому «необходимо задаться вопросами о психологических, социальных и политических условиях, в рамках которых мюди помнят или забывают, а также об эмоциях, которые при этом мобилизуются или заглушаются” ${ }^{4}$

М. Хамьбвакс разделяет пережитое и узнанное, автобиографическую память и память историческую. Первая память использует вторую. Но цичная память может быть бесконечно трагична, что блокирует ее широкую трансляцию, ибо для носителей этого опыта он чрезвычайно травматичен. На это накладывается проблема политического контроля, идеологических допусков, цензурных рамок.

И. Савельева и А. Полетаев принимали классификацию "мест памяти", предложенную П. Нора, хотя и иронизировали по поводу именования "местами", например, учебников (сами они употребляют слово "функционал»). Они солидаризируются с А. Ассманом в том, что «память о прошиом не имеет ничего общего с научной историей" и обращают внимание на то, что массовые представления о прошлом также не имеют с ней ничего общего. Всеохватывающая система школьного образования не воспрепятствовала сильному содержательному отличию массовых знаний истории от профессиональных. В результате, «если то, что помнят о прошиом, зависит от способа его репрезентации, то образ прошлого в массовом сознании должен соответствовать скорее социальному заказу, чем задачам исторического познания" ${ }^{5}$.

П. Нора пишет о современном "расцвете памяти" и видит два важных следствия из факта этого расцвета. "Первое состоит во все более интенсивном использовании прошлого - политическом, туристическом, коммерческом. Это проявияось в резком подъеме мемориальных мероприятий, особенно заметном во

\footnotetext{
3 Ibidem.

4 А. Ассман, Забвение истории - одержимость историей, Москва 2019, с. 17.

5 Смотри шире: И.М. Савельева, А.В. Полетаев, "Историческая память": $\kappa$ вопросу о гранииах понятия, [в:] Феномен прошлого, ред. И.М. Савельева, А.В. Полетаев, Москва 2005, с. 170-220.
} 
Франции"б. "Мемориальное изобилие" доказывает, что "прошлое утратило единый смысл и что настоящее, наделенное историческим самосознанием, неизбежно узаконивает множественность возможных версий прошлого»7. Второе следствие - это потеря монополии историка на контроль над прошиым. Сегодня в этой роли выступают и СМИ, и судьи, и свидетели, и законодатели. Память становится не только средством сохранения и объединения, но и исключения и вражды ${ }^{8}$.

Таким образом, можно констатировать повышение активности и даже агрессивности прошиого в настоящем, причем усилия профессионального сообщества историков оказываются не единственными в этом процессе, а сами картины прошлого неизбежно раздваиваются в научных, мемориальных и "профанных" практиках. Значит, возникает вопрос о степени исторической проработанности тех или иных сюжетов и общественной солидарности по их поводу. Войны неизбежно оставцяют о себе глубокое впечатмение. Во внешней войне победители и побежденные рождают свою более или менее отрефлексированную память. В гражданских войнах случается по-другому. Во Франции, благодаря Реставрации, даже простонародные участники Вандейских войн не просто получили воздаяние за преданность, но и оставили воспоминания (недавно в России вышла книга о таком персонаже "вандейской Жанне д’Арк" Рене Бордеро ${ }^{9}$ ). Детально и с обеих сторон изучена Грахданская война в САСШ (при этом споры продолжаются, размичия в оценках не исчезают, происходят атаки на памятники), свои голоса давно имеют стороны испанской гражданской войны. В исторической науке Франции, Соединенных Штатов и других стран европейской интелмектуальной традиции многие сюжеты разработаны с максимально возможной подробностью. Сцедующим этапом закономерно становится изучение феноменов памяти, интер-

\footnotetext{
6 П. Нора, Всемирное торжество памяти, „Неприкосновенный запас”, 2005, № 2, https://magazines.gorky.media/nz/2005/2/vsemirnoe-torzhestvo-pamyati.html (дата доступа: 28.11.2020).

7 Ibidem.

8 Ibidem.

9 В.А. Шурыгин, Рене Бордеро по прозвищу Анжуеи. За Бога и Короля. Выпуск 21, Москва 2019.
} 
претаций, оценок и т.п. В этой связи возникает даже "мемориальная индустрия", несущая сепаратистские и другие подобные риски дмя сегодняшнего состояния общества, по мнению К. Майера и других ${ }^{10}$.

Применительно же к отечественной истории "комлективная (в т.ч. групповая) память находится в неоднозначных отношениях с официальной политикой памяти, вытекающей из задаваемой свыше госидеологии» ${ }^{11}$. Идеологическая официализация одной части комлективной памяти и угнетение другой особенно ярко проявляется на материале Гражданской войны, в частности, в образах низовой, местной вражды.

В символическом пространстве дела с противостоянием обстояли достаточно благополучно. Авторы и сценаристы не забывали "другую сторону", ибо она нужна была дмя решения художественной или идеологической задачи. Даже безусловно трагические и страшные события могми подниматься на щит в идейном пространстве борьбы старого и нового, отсталого и прогрессивного. Со временем бескомпромиссность перестала педалироваться, хотя сам идеологический вектор не менялся. Так, в шолоховском Бахчевнике от рук отца гибнет мать, от рук сына отец. А в позднесоветском фильме «Первая конная" (1984) противостояние братьев-красноармейцев и старика-казака - их отца кончается вполне благополучно, с милым комикованием на фоне окончательной победы красной конницы над казачьими полками. При этом всегда подразумевалась неизбежная монолитность и многочисленность красных. Характерное название фильма 1958-го года "Юность наших отцов" не оставляло места для вопрошаний об отцах "ненаших".

Советская идеология и практика мемориализации была направлена не столько на сохранение памяти о конкретных мюдях, стяжавших славу, сколько на тиражирование "положительного" примера в воспитательных целях. Отсюда и пренебрежительное отношение к исторической достоверности, с "корректировкой" дат, высказываний, подробностей, и т.п. При этом существовали нежелательные сюжеты, запретные имена,

\footnotetext{
10 А. Ассман, Новое недовольство мемориальной культурой, Москва 2016. 11 А.В. Святославский, История России в зеркале памяти. Механизмы формирования исторических образов, Москва 2013, с. 300.
} 
а также предписывался определенный дискурс изложения безрефмексивный, напористо-победный. Мемуаристам приходимось на протяжении жизни довольно круто менять "воспоминания", но это связывалось, как правило, с конъюнктурными обстоятемьствами. Например, герой-командир, под началом которого ты сражался, оказывался с какого-то момента врагом народа, и очередные анкетные, мемуарные, устные версии приходилось выстраивать так, чтобы дистанцироваться от близости с нежелательной персоной. Магистральное же представление о Гражданской войне, правых и виноватых в ней не менялось.

В России, помимо, условно говоря, "офицерской" белой памяти, казаки большинства казачьих войск, рабочие-уральцы сформировали богатую мемуарную митературу и долгую память

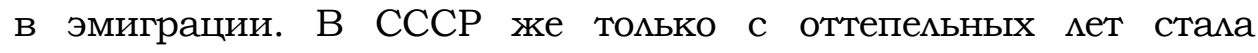
допустимой "своя правда", заведомо ущербная, на белой стороне. Кинематограф дал ряд ярких примеров подобных киногероев. Однако эта новация очень мало коснулась низового уровня, уровня уездного города - села. Низовая, сельская, живая память почти не вырвалась за пределы мокального мира.

Во множестве бывших уездных городов и сец организация пространства включает в себя памятные места смерти: захоронения павших за советскую власть в скверах и на площадях и соответствующая инфраструктура мемориализации. В этом ключе строились экспозиции краеведческих музеев, работа школьных музеев и кружков, военно-патриотическая деятельность, сбор мемуаров организаторов советской власти, красногвардейцев, красных партизан, первых комсомомьцев. Яркости героя соответствовал безцикий, в виде "кулаков", "предателей" и т.п., мир врагов и противников. Вражеская сторона оказывалась классическим "молчаливым", то есть безцичным, большинством.

Важно при этом, что многолетнее одностороннее комплиментарное внимание к активному революционному меньшинству подразумевало, что большинство местных жителей или сочувствует и помогает ему, или "временно заблуждается" под вциянием врагов. Такая схема явцяется беспроигрышной, но нуждается в тоннельном зрении ее потребителей, при отсутствии 
множественности мнений, их динамики, понимания, какие группы в деревне противостояли друг другу. Разбор данных сюжетов начинается сегодня, когда живых носителей памяти о событиях 1917 - начала 1920-х уже нет. Таким образом задается повод дмя дальнейших искажений и эмоциональной неправды в восприятии прошлых событий столетней давности на низовом уровне.

Итак, нам приходится иметь в виду отсутствие вполне реальных, активных и многочисленных акторов в пространстве памяти. Свидетельские, нейтральные воспоминания еще существуют, и известны благодаря усилиям историков и краеведов. Так, введены в научный оборот воспоминания свидетелей Тамбовского восстания 1920-1921 гг. ${ }^{12}$ Голоса же активных противников красных, тех, кто поднимал села на восстания или уходиц из родных мест, практически не слышны. Остаются только косвенные сведения: воспоминания представителей "большого" мира, данные политического наблюдения красных и белых инстанций, их же следственно-судебные материалы. Эти мюди, в мучшем случае, говорят с нами языком трибунальских протокомов.

Кем представлена эта "другая" сторона? Организаторами, иногда ситуативными, восстаний, добровольцами Белых армий, активными дезертирами, "кулаками", которые боролись за власть в советах, бывшими красными командирами, которые подняли оружие после коммунистов в 1920-1921 гг. На их стороне часто бывало сочувствие большой или явно бомышей части деревни. Однако в памяти педалируемая в пространстве официоза "беззаветная" храбрость (преданность, бескопромиссность и т.п.) коммунистического меньшинства выигрывала в сравнении с часто конформным поведением тех же "кулаков" и дезертиров. Политический экстремизм в идеологически направляемой памяти выигрывает у негероического, ориентированного на

12 См. напр.: А.В. Власов, Они видели "антоновщину" (события 1920-1921 г2. в Тамбовской губернии в воспоминаниях младших современников), [в:] "Атаманшина" и "партизаншина" в Гражданской войне: идеология, военное участие, кадры. Сборник статей и материалов, ред. А.В. Посадский, Москва 2015, с. 496-518; В.В. Поляков, Свидетели восстания, [в:] Тамбовское восстание1920-1921 г2.: исследования, документы, воспоминания, ред. А.В. Посадский, Москва 2018, с. 278-282. 
неразрушительные практики, поведения болышинства населения. Возможно, отчасти из-за этого сегодня набцюдается ренессанс мюбви к советскому в прямую противоположность массовым настроениям столетней давности. У этой части деревни не бымо не только голоса, но и языка. По этой причине также у нас сегодня практически отсутствует нешаржированный образ противников нового строя на низовом уровне.

В перестройку и начале 1990-х гг. появился феномен внезапного начала публичных воспоминаний старожилов. Вспоминались судьбы "некрасных" персонажей, необозначенные братские могимы в окрестностях и иные подобные сюжеты. Если эти рассказы находими благодарных слушателей или интерес местных краеведов, они имели шанс попасть в публичное пространство. А так случалось далеко не всегда. В условиях жестокого подавцения «антисоветская" память неизбежно уходима в устную традицию. А она, в свою очередь, также постоянно испытывала гнет страха и самоцензуры и к моменту вспышки интереса к событиям Гражданской войны практически исчерпалась в своих живых носителях, в большинстве случаев не будучи перенесенной на бумагу.

Нет источников - нет и памяти, нет и образа этих мюдей в массовом сознании, есть простор дия мифотворчества, как низового, так и идеологического. Действитемьно, можно встретить в краеведческой митературе или устной традиции истории, походящие на апокрифы. Например, о случайной встрече в поезде, когда незнакомый попутчик вдруг цепко расспрашивает собеседника о родном селе, не распространяясь о себе и не объясняя причины интереса. Или позднесоветские истории о приезде в деревню некоего иностранца, в котором местный старик признает прежнего барина. Одной из форм исторической памяти в сельском пространстве выступали прозвища, как отдемьных миц, так и целых селений. Прозвища часто давали прямую отсылку к какому-либо забавному, славному или позорному событию в жизни селения. Сегодня некоторые активные повстанческие села в Прихоперье до сих пор зовут 
"зеленовщина". Однако с исчезновением активной сельской жизни эта традиция неизбежно уходит ими музеефицируется ${ }^{13}$.

Местная деревенская вражда, часто завязанная на противостоянии и обидах семей, кланов, деревенских «концов» и "улиц" требует сохранения того же пространства, той же конфигурации. Иначе помнить "нечего", важные нюансы забываются из-за изменения сельского пространства, переезда в города ими же равнодушия потомков, а для неместньх энтузиастов все эти подробности просто невозможно адекватно уяснить. При этом даже в соседних селах может очень по-разному смениться население. В одном - через четыре поколения еще сохраняется костяк коренных семей, в другом - практически никого не остается. Такие примеры имеются на территории прежнего Камышинского уезда Саратовской губернии, в тех селах, на базе которых в 1918 г. разворачивалось самоуправление и местная антибомьшевистская сила - Саратовский корпус ${ }^{14}$.

K тому же официальное пространство памяти в сельской местности нередко представлено вообще неместными мюдьми. Например, это погибшие продотрядовцы - частый скучай, погибшие при подавлении "кумацких" восстаний, организаторы советской власти, опять-таки нередко из пришлых. Старинный Романов-Борисоглебск на Волге получиц имя неместного, убитого в случайной перестрелке, красноармейца Ильи Тутаева. Иногда фамимии на революционных памятниках вызывающе чужды дмя русского слуха вообще; это, как правило, поименно известные "интернационалисты" немецкого и венгерского происхождения. Таковы, например, памятные плиты на набережной Симбирска (Умьяновска), которыми увековечена память погибших при подавлении Чапанной войны 1919-го года.

В провинции осталась нетронутой вся революционная топонимика. В райцентрах и тем более в селах не было переименований или возвращения прежних названий, как в Москве и крупных городах ${ }^{15}$. Сгущение чужих имен, навязанных

13 А.В. Посадский, Зеленое движение в гражданской войне России в России. Крестьянский фронт между красными и бельми, Москва 2018.

14 А. Посадский, Полковник В.К. Манакин и Саратовский корпус. Эпизод гражданской войны, Москва 2018.

15 Тем не менее, следует отметить, что даже в крупных городах многие попытки изменения наименования оказались безуспешными. Пример - город 
в первые поревоцюционные годы, особенно заметно в неболышом пространстве. Именно там, где названия говорящие, напоминающие об истории заселения, особенностях местности и т.п. Например, в воронежском селе Новая Чигла, которое около двадцати раз переходимо из рук в руки на протяжении 1918-1920 гг. на четыре десятка названий умиц и проездов буквально

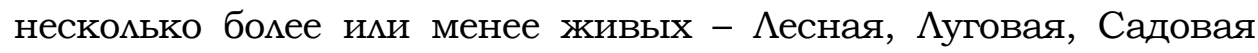
и проч. Остальные названия представцены всем букетом вождей и героев от Свердмова и Буденного до Мичурина и Горького, советских праздников и производньх от слов "народ", "пролетариат" и подобных. Данный пример вполне типичен.

Таким образом, официозная память может оказываться в "паралцельном" реальной памяти пространстве. $\Lambda$. Репина полагает, что «целостность мифологического полотна памяти с течением времени (при отсутствии катастроф глобального масштаба), как правило, восстанавцивалась", приводя в пример английское умение хранить живую преемственность. C.А. Экштут, напротив, обращает внимание на точки разрыва, точки забвения, белые пятна и фигуры умолчания ${ }^{16}$. В российской истории прошлого столетия последнее, увы, оказывается более актуальным.

По авторитетному мнению М. Громыко ${ }^{17}$, крестьянская память была весьма глубока и структурирована, с неизменным интересом к местным событиям. Воспоминания сельских жителей редко бывают политически ориентированы, и вообще рефлексия в политических терминах вряд $\Lambda и$ возможна в их среде. Так, предводители крупных восстаний, прежде всего С. Разин, понимались в диапазоне от "благородного разбойника" до "кары Божией». Поэтому историческая память в некоторых случаях развивается по фольклорной минии. Местные повстанцы

Киров. Несмотря на размичные инициативы, ему не вернули прежнее название Вятка. А. Бобрык, І. Кохан, Гістарычная палітыка ў назвах гарадоў. Прыклад Кірава, [в:] Менталитет славян и иртеграиионные проиессы: история, современность, перспекмивы (Материаль VI международной научной конферениии 21-22 мая 2009 г., г. Гомель), гм. ред. В.В. Кириенко, Гомель 2009, с. 159-161.

16 М.П. Репина, Опьт соииальных кризисов в исторической памяти, [в:] Кризисы переломных эпох в исторической памяти. ред. А.П. Репина, Москва 2012, c. 29-30.

17 М.М. Громыко, Мир русской деревни, Москва 1991. 
ставятся в один ряд с былинными персонажами, как Огомьцов на Рязанщине ${ }^{18}$, или же просто становятся предметом подражания, игры, которая, в свою очередь, дает новые поводы дмя запоминания, интереса, рецепции памяти. Как правило, такая память мокальна и касается только той местности, в которой когда-то развивались военно-политические события. Такова, например, история "Юшки" - Ефима Скородумова в районе Юрьев-Польского, история Кости Озерова на Ярославщине.

Немалое значение имеет присваивание революционносоветского опыта как своего не только в силу обстоятельств или по факту рождения, а как правикьного, выстраданного и естественного. Это надо считать могичным дмя русских - стержневого имперского этноса, который, волею судеб, переориентировался с одной имперской могики существования на иную, псевдоимперскую. Дия других народов посткоммунис-тического пространства ближе оказываются дискурсы освобождения, рождения национальной государственности, преодоления оккупации, возвращения к прерванной традиции и т.п. Отсюда табуирование и маргинализация в русском сознании противоположного пути в истории, пререкаемых фигур не только бомьшой, но и местной истории.

Однако некоторые вещи местная память хранила весьма прилежно. На наш взгляд, главным оказывались места бессудных убийств, братские могимы. Такие места домго помнимись, упрямо обозначались, несмотря на усилия властей по недопущению несанкционированной памяти, им давались названия типа "убитый яр". Так, например, помнилась братская могила расстрелянных нескольких десятков человек в начале весны 1919 г. в большом селе Бакуры Сердобского уезда Саратовской губернии. В костромском селе Красное местная память устойчиво

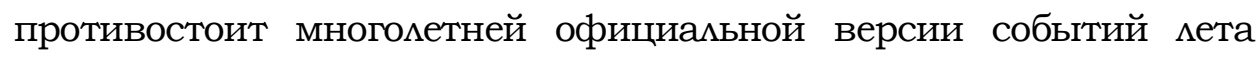
1919-го года. Победный бой красного отряда с бело-зелеными в официальном изложении - местными жителями помнится и оценивается как кровавая расправа над безоружными с сожжжением деревень и глумлением над мюдьми. Если обратиться

18 В.А. Пылькин, Крестьянство Центра России в гражданской войне. Обиественно-политические настроения, соииальные проиессы, протест, Рязань 2005, с. 249-250. 
к традиции христианской мемориализации ${ }^{19}$, мы не увидим ничего похожего в советском дискурсе - ни памятных крестов, ни часовен, ни памятных надписей, ни даже самого христианского погребения. Видимо, мощная христиан-ская традиция нашла свое выражение в этом неофициальном почитании как безвинно погибших, так и в бою убиенных. Возможно усмотреть в этом также мотив покаяния и рефмексии по поводу столь азартно-кровавой борьбы в начале ХХ века.

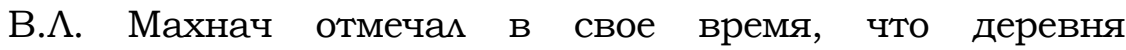
консервирует все 20 , ныне она консервирует советское прошиое.

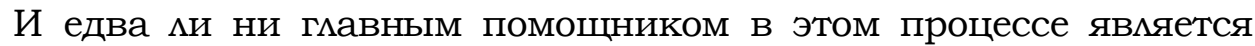
отсутствие альтернативных голосов, памяти и традиции. Данное обстоятельство создает особенно резкую акцентировку в известной формуле "историю пишут победители" и рождает проблему дия исследователя - всегда помнить, что как источниковая база, так и традиция памяти по тематике пореволюционной жизни сильно деформированы. Можно надеяться, что вызвать к жизни неуслышанных персонажей можно не только с помощью мифологизации и карнавализации прошлого, но и на рациональном базисе неразработанных еще источников, поисковой деятельности и востребования (где возможно!) комлективной памяти о событиях первых поревоцюционных мет. Можно полагать, что посильное исправление данной деформированной ситуации способно дать ответ на вопрос о сравнении запаса жизнестойкости и в целом экзистенциальных практик русского провинциального жителя - сторонника революции и его соседа, для которого революции выглядела как сила враждебная, как хаос и подрыв привычных основ жизни.

\section{Бибмиография / References}

Assman A., Novoe nedovol'stvo memorial'noj kul'turoj, Moskva 2016. [Ассман А., Новое недовольство мемориальной культурой, Mосква 2016].

Assman A., Zabvenie istorii - oderžimost' istoriej, Moskva 2019. [Ассман A., Забвение истории - одержимость историей, Москва 2019].

19 См.: А.В. Святославский, Традииия памяти в Православии, Москва 2004.

20 В. Махнач, Мы живем в нерусском городе, https://1kle.livejournal. com/ 11639.html (дата доступа: 28.11.2020). 
Bobryk A., Kohan I., Gìstaryčnaâ palìtyka ǔ nazvah garadoǔ. Pryklad Kìrava, [v:] Mentalitet slavân i integracionnye processy: istoriâ, souremennost', perspekmivy (Materialy VI meždunarodnoj naučnoj konferencii 21-22 maâ 2009 g., g. Gomel'), red. V.V. Kirienko (gl. red.), Gomel' 2009. [Бобрык А., Кохан I., Гістарычная палітыка ў назвах гарадой. Прыклад Кірава, [в:] Менталитет славян и интеграиионные проиессы: история, современность, перспекмивы (Материаль VI международной научной конферениии 21-22 мая 2009 г., г. Гомель), ред. В.В. Кириенко (гц. ред.), Гомель 2009].

Gromyko M.M., Mir russkoj derevni, Moskva 1991. [Громыко М. М., Мup русской деревни, Москва 1991].

Hal'bvaks M., Kollektivnaâ $i$ istoričeskaâ pamât', „Neprikosnovennyj zapas” 2005, № 2, https://magazines.gorky.media/nz/2005/2/ kollektivnaya-i-istoricheskaya-pamyat.html (data dostupa: 28.11.2020). [Хальбвакс М., Коллективная и историческая память, „Неприкосновенный запас” 2005, № 2, https://magazines.gorky. media/ nz/2005/2/kollektivnaya-i-istoricheskaya-pamyat.html (дата доступа: 28.11.2020)].

Mahnač V., My živem $v$ nerusskom gorode, https://1kle.livejournal. com/11639.html (data dostupa: 28.11.2020). [Махнач В., Мы живем в нерусском городе, https://1kle.livejournal. com/11639.html (дата доступа: 28.11.2020)].

Nora P., Vsemirnoe toržestvo pamâti, „Neprikosnovennyj zapas” 2005, № 2, https:/ / magazines.gorky.media/nz/2005/2/vsemirnoe-torzhestvopamyati.html (data dostupa: 28.11.2020). [Нора П., Всемирное торжество памяти, „Неприкосновенный запас” 2005, № 2, https:/ / magazines.gorky.media/nz/2005/2/vsemirnoe-torzhestvopamyati.html (дата доступа: 28.11.2020)].

Polâkov V.V., Svideteli vosstaniâ, [v:] Tambovskoe vosstanie 1920-1921 gg.: issledovaniâ, dokumenty, vospominaniâ, red. A.V. Posadskij, Moskva 2018. [Поляков В.В., Свидетели восстания, [в:] Тамбовское восстание 1920-1921 г2.: исследования, документы, воспоминания, ред. А.В. Посадский, Москва 2018].

Posadskij A.V., Polkounik V.K. Manakin i Saratouskij korpus. Èpizod graždanskoj vojny, Moskva 2018. [Посадский А.В., Полковник В.К. Манакин и Саратовский корпус. Эпизод гражданской войны, Mосква 2018].

Posadskij A.V., Zelenoe dviženie $v$ graždanskoj vojne Rossii $v$ Rossii. Krest'ânskij front meždu krasnymi i belymi, Moskva 2018. [Посадский А.В., Зеленое движение в гражданской войне России в России. Крестьянский фронт между красньмии и бельмии, Москва 2018].

Pyl'kin V.A., Krest'ânstvo Centra Rossii vgraždanskoj vojne. Obŝestvennopolitičeskie nastroeniâ, social'nye processy, protest, Râzan' 2005. [Пьлькин В.А., Крестьянство Центра России в гражданской 
войне. Общественно-политические настроения, соииальные проиессы, протест, Рязань 2005].

Repina L.P., Opyt social'nyh krizisov $v$ istoričeskoj pamâti, [v:] Krizisy perelomnyh èpoh $v$ istoričeskoj pamâti, red. L.P. Repina, Moskva 2012. [Репина К.П., Опыт соииальных кризисов в исторической памяти, [в:] Кризисы переломных эпох в исторической памяти, ред. А.П. Репина, Москва 2012].

Savel'eva I.M., Poletaev A.V., "Istoričeskaâ pamât"»: $k$ voprosu o granicah ponâtiâ, [v:] Fenomen prošlogo, red. I.M. Savel'eva, A.V.Poletaev, Moskva 2005. [Савельева И.М., Полетаев А. В., "Историческая память»: $\kappa$ вопросу о границах понятия, [в:] Феномен прошлого, ред. И.М. Савельева, А.В. Полетаев, Москва 2005].

Šurygin V.A., Rene Bordero po prozviŝu Anžuec. Za Boga i Korolâ. Vypusk 21, Moskva 2019. [Шурыгин В.А., Рене Бордеро по прозвищу Анжуеи. За Бога и Короля. Выпуск 21, Москва 2019].

Svâtoslavskij A.V., Istoriâ Rossii v zerkale pamâti. Mehanizmy formirovaniâ istoričeskih obrazov, Moskva 2013. [Святославский А.В., История России в зеркале памяти. Механизмы формирования исторических образов, Москва 2013].

Svâtoslavskij A.V., Tradiciâ pamâti $v$ Pravoslavii, Moskva 2004. [Святославский А.В., Традиция памяти в Православии, Москва 2004].

Vlasova.V., Oni videli "antonovŝinu" (sobytiâ 1920-1921 gg. v Tambouskoj gubernii v vospominaniâh mladših sovremennikov), [v:] "Atamanŝina"i "partizanŝina" $v$ Graždanskoj vojne: ideologiâ, voennoe učastie, kadry. Sbornik statej i materialov, red. A.V. Posadskij, Moskva 2015. [ВАасов А.В., Они видели "антоновщину" (события 1920-1921 г2. в Тамбовской губернии в воспоминаниях младших современников), [в:] "Атаманшина" и "партизанщина" в Гражданской войне: идеология, военное участие, кадры. Сборник статей и материалов, ред. А.В. Посадский, Москва 2015]. 